\section{Re: Reporting and Using Near-Miss Events to Improve Patient Safety in Diverse Primary Care Practices: A Collaborative Approach to Learning from Our Mistakes}

To the Editor: Near-miss reporting systems are a valuable tool for identifying errors that could cause patient harm. ${ }^{1}$ Crane et $\mathrm{al}^{2}$ demonstrated the feasibility of implementing these systems in diverse ambulatory care settings. However, the large financial incentives of both implementation and continued reporting of events limits the interpretation of this study. Large monthly monetary rewards for a set quantity of reports are likely to cloud the intention of near-miss reporting: to reduce errors that could cause patient harm.

There is certainly a monetary cost to the orientation and training required to implement a near-miss reporting system, yet the amount allotted in this study seems to far exceed typical costs. Even more concerning is the $\$ 1500$ monthly incentive for reporting near-miss events and identifying an event to track. These monthly payments are a major potential bias regarding the quality and office buy-in of near-miss reporting. The authors defend these bonuses by stating that reporting continued after the payouts ceased, and that, based on group interviews, there were no concerns of staff feeling pressured to report. However, group interviews are not adequate to assess this issue because staff may not feel comfortable reporting these concerns without the opportunity to provide anonymous individual feedback. Even if there was no pressure to report, the inherent bias of these monetary incentives still stands. A simple way to eliminate this bias is to not include monetary incentives at all. Multiple studies demonstrate that near-miss reporting systems without a monetary incentive can be successful. ${ }^{3-5}$ These studies all note an increase in the reporting of near-miss events after implementation, similar to the findings in the study by Crane et al. ${ }^{2}$ Our office uses a paper-based near-miss reporting system with office recognition of those members who consistently report. Each month our physicians and staff share the "good catches" with each other to reinforce good reporting practices. There are no monetary rewards, yet the quantity and quality of reporting has remained steady since implementation over 2 years ago.

A monetary incentive may assist in the implementation of near-miss reporting systems, but it may jeopardize the quality of reporting. For a practice to conduct quality near-miss reporting, the primary incentive for reporting should be to improve patient care. Large monetary incentives may shift this goal to reaching a monthly quantity of reporting events, and the quality or relevance of these reports could suffer. The model presented in this article may be useful for implementing a near-miss re- porting system in settings that are not otherwise inclined to do so, but incentives should be cost-neutral at most. If possible, an ideal near-miss reporting system would be strictly voluntary, without monetary incentives, to avoid a major source of bias and keep the focus on improving patient care.

Stephen E. Auciello, MD Riverside Methodist Hospital Family Medicine Residency Program Columbus, $\mathrm{OH}$ Stephen.Auciello@ohiohealth.com

\section{References}

1. Noble DJ, Panesar SS, Pronovost PJ. A public health approach to patient safety reporting systems is urgently needed. J Patient Saf 2011;7:109-12.

2. Crane S, Sloane PD, Elder N, et al. Reporting and using near-miss events to improve patient safety in diverse primary care practices: a collaborative approach to learning from our mistakes. J Am Board Fam Med 2015;28:452-60.

3. Hickner J, Zafar A, Kuo GM, et al. Field test results of a new ambulatory care Medication Error and Adverse Drug Event Reporting System-MEADERS. Ann Fam Med 2010;8:517-25.

4. Plews-Ogan ML, Nadkarni MM, Forren S, et al. Patient safety in the ambulatory setting. A clinician-based approach. J Gen Intern Med 2014;19:719-25.

5. Kostopoulou O, Delaney B. Confidential reporting of patient safety events in primary care: results from a multilevel classification of cognitive and system factors. Qual Saf Health Care 2007;16:95-100.

doi: 10.3122/jabfm.2016.01.150286

The above letter was referred to the authors of the article in question, who offer the following reply.

\section{Response: Re: Reporting and Using Near-Miss Events to Improve Patient Safety in Diverse Primary Care Practices: A Collaborative Approach to Learning from Our Mistakes}

To the Editor: We appreciate the thoughtful letter from Dr. Auciello regarding our article "Reporting and Using Near-Miss Events to Improve Patient Safety in Diverse Primary Care Practice." ${ }^{1}$ Dr. Auciello's primary concern is that "large monthly monetary rewards for a set quantity of reports is likely to cloud the intention of near-miss reporting: to reduce errors that could cause patient harm." Specifically, he suggests that financial compensation to report near-miss events and performance improvement activities to a common database introduces potential bias to the quality of these reports, and may be unnecessary.

While we did compensate practices for costs related to participating in the collaborative, this reimbursement 
was by no means "large," and probably under-represented the actual costs practices incurred from their involvement in the project. Each practice received \$5000 to implement the project, which included a 90-minute orientation for key practice leaders (a physician champion and the practice manager, at a minimum), a 60-minute training for all staff, and installing the near-miss reporting icon on all desk top computers in the practice. Many practices incurred additional costs from legal counsel, risk management consultants, and information technology department staff who had to review the project and agree that the practice could participate. Once implemented, practices received an additional $\$ 1500$ per month, for which they were expected to have their practice manager and physician champion participate in a monthly hour-long conference call, review near-miss reports, implement practice improvement projects resulting from the near-miss reports, and hold all-staff safety meetings once a month. Practices were not paid per near-miss report; rather, they received the monthly stipend only if they met the minimum participation criteria, which included at least 10 reports a month.

These payments were not large when considering the median practice volume was $>2000$ patient visits a month. Although we did not report the average monthly income for the participating practices, the monthly stipend would have represented $<0.1 \%$ of gross income for the typical practice. This amount would be highly unlikely to provide a strong incentive to over-report.

Moreover, only 2 practices made any attempt to share even a portion of the monthly stipend with practice staff. In one case a practice provided lunch for the staff during their monthly safety/quality improvement meeting, and in the other a practice provided a drawing for a \$25 gift card if the practice met its reporting goal. Given that the reports themselves were anonymous and staff did not receive any individual inducement to report near-miss events, there seems to be little incentive to over-report or otherwise bias the reporting process. Furthermore, we did not observe any difference between either the number or type of near-miss reports from those 2 practices and those from the other practices that did not provide any monetary or in-kind reward to staff.

Dr. Auciello suggests that for near-miss reporting, the "primary incentive should be to improve care," and reports that his own practice has a "good catch" program as part of the internal performance improvement curriculum of his residency program. We commend him and his program for this but suggest that this is rare, even for residency programs, and is almost unheard of in primary care practices.

With respect to the larger issue of "pay for performance," there is a growing movement among payers to provide substantial incentives for quality reporting and performance improvement, including the Centers for Medicare and Medicaid Services Physician Quality Reporting System ${ }^{2}$ and meaningful use incentives, ${ }^{3}$ as well as private payer incentive programs for quality. ${ }^{4}$ Physicians do indeed have a responsibility to care about the quality and safety of the care they provide to patients; despite this, however, medical errors continue to plague the medical care system. ${ }^{5}$

There are real costs associated with identifying and correcting near-miss events. Given that primary care is already undercapitalized and understaffed relative to hospitals, and that primary care physicians are undercompensated relative to specialty colleagues, who should bear these costs of practice improvement? Absent a market for consumers (patients) to have information regarding safer practices to reward those practices with greater volume and an enhanced payer mix, we believe that payers themselves would be well served by creating safety incentive payments for practices that engage in safety improvement programs, since safer care is undoubtedly less expensive over the long term. From this perspective, there should be considerably more incentive payments for safety improvement efforts rather than relying solely on the professionalism of overworked primary care physicians.

An advantage of a near-miss reporting and improvement collaborative such as our project is the opportunity to learn from each other and reduce the cost of innovation and improvement. If I can learn from your mistake I do not have to make that mistake myself; more important, working together we can build a safer primary care system for all our patients.

Steven D. Crane, MD

Mountain Area Health Education Center University of North Carolina-Chapel Hill

Asheville, NC

steven.crane@msj.org

Philip D. Sloane, MD

University of North Carolina-Chapel Hill Chapel Hill, NC

Nancy Elder, MD

University of Cincinnati

Cincinnati, $\mathrm{OH}$

Lauren Cohen, MA

University of North Carolina-Chapel Hill

Chapel Hill, NC

Natascha Laughtenschlaeger, MD Mountain Area Health Education Center Asheville, NC

Kathleen Walsh, BA

Mountain Area Health Education Center Asheville, NC

Sheryl Zimmerman, $\mathrm{PhD}$

University of North Carolina-Chapel Hill Chapel Hill, NC

\section{References}

1. Crane S, Sloane PD, Cohen L, et al. Reporting and using near-miss events to improve patient safety in diverse primary care practice. J Am Board Fam Med 2015;23: 452-60.

2. Centers for Medicare \& Medicaid Services. Medicare EHR incentive program physician quality reporting system and electronic prescribing incentive program comparison. May 2013. Available from: https://www.cms.gov/regulations-andguidance/legislation/ehrincentiveprograms/downloads/mln_ 
medicareehrprogram_pqrs_erxcomparison.pdf. Accessed September 26, 2015.

3. Centers for Medicare \& Medicaid Services. Electronic health records (EHR) incentive programs. October 29, 2015. Available from: https://www.cms.gov/Regulations-and-Guidance/ Legislation/EHRIncentivePrograms/index.html? redirect =/ ehrincentiveprograms. Accessed September 26, 2015.

4. Blue perspective. Value-based programs. Washington, DC: BlueCross BlueShield Association; 2014. Available from: http:// www.bcbs.com/healthcare-news/press-center/BP-and-Qualityand-Plan-Innovations.pdf. Accessed September 26, 2015.

5. Institute of Medicine. Crossing the quality chasm: a new health system for the 21st century. March 2001. Available from: https://iom.nationalacademies.org/ /media/Files/ Report\%20Files/2001/Crossing-the-Quality-Chasm/ Quality\%20Chasm\%202001\%20\%20report\%20brief.pdf. Accessed November 18, 2015.

doi: 10.3122/jabfm.2016.01.150320

\section{Re: Clinical Decisions Made in Primary Care Clinics Before and After Choosing Wisely ${ }^{\mathrm{TM}}$}

To the Editor: Kost and Genoa demonstrated that physician adherence to guidelines for 5 low-value clinical decisions improved through educational interventions. ${ }^{1}$ They concluded that "primary care physicians respond to training and publicity in low-value care." This intervention strategy decreased physician-initiated testing that provide little clinical value. In this way, the Choosing Wisely initiative may help to achieve the health care triple aim. ${ }^{2}$ However, the authors failed to explain why there were drastic differences in responses among the intervention groups. Of the 5 clinical decisions that were targeted, 2 groups (antibiotics for acute sinusitis, dualenergy X-ray absorptiometry for osteoporosis screening) improved in adherence markedly, and 3 groups (cervical cancer screening, heart disease screening, back pain imaging) did not change significantly. This disparity merits thoughtful discussion and a call for further research.

The authors propose that the groups showing no improvement shared very high adherence before the intervention, "limiting the opportunity for change." This is one plausible explanation for the lack of improvement in these 3 groups. However, there are numerous other possible explanations for the difference in improvement. Perhaps different clinical decision groups were subjected to different interventions, and thus produced different results. The article states that groups were provided with an in-person seminar or a webinar, but does not reveal which groups had each intervention. Active learning is superior to lecture for learner retention. ${ }^{3}$ If the groups that improved were given the webinar, this could account for their change. The difference may also be explained by confounding variables. Avoiding certain low-value decisions may have been reinforced outside of the study. Billboards, posters, or other resident lectures may have given publicity to the lack of value in giving antibiotics for sinusitis, for example. If residents were not exposed to similar materials on back pain, this inequality could have caused the differences found by the authors. Examining every possible reason for the difference may not have been within the authors' intent. However, the identification of different responses to their intervention strategy is important. It is a loss to allow the difference to disappear by averaging all 5 groups together.

The goal of the Choosing Wisely initiative is to expose clinical decisions whose necessity should be questioned or discussed. ${ }^{4}$ This article clearly highlights one way to help reach the initiative's goal. It shows that physicians respond to education regarding certain clinical decisions. However, it just as clearly shows that some low-value decisions did not change as a result of educational interventions. To achieve the health care triple aim, we must discover interventions that will help physicians avoid low-value testing. We cannot reach this ideal without thoughtful examination of both successful and unsuccessful interventions for low-value decisions.

Joseph B. Gladwell, MD

Riverside Family Medicine Residency

Columbus, $\mathrm{OH}$

Joseph.Gladwell@ohiohealth.com

\section{References}

1. Kost A, Genao I, Lee JW, Smith SR. Clinical decisions made in primary care clinics before and after Choosing Wisely. J Am Board Fam Med 2015;28:471-4.

2. IHI triple aim initiative. Cambridge, MA: Institute for Healthcare Improvement. Available from: http://www.ihi. org/engage/initiatives/tripleaim. Accessed August 28, 2015.

3. Mains TE, Cofranscesco J, Milner SM, Shah NG, Goldberg $\mathrm{H}$. The impact of audience response systems on medical student learning. Postgrad Med J 2015;91:361-7.

4. Choosing Wisely [homepage]. Philadelphia: ABIM Foundation. c2015. Available from: www.choosingwisely.org. Accessed August 28, 2015.

doi: 10.3122/jabfm.2016.01.150287

The above letter was referred to the authors of the article in question, who offer the following reply.

\section{Response: Re: Clinical Decisions Made in Primary Care Clinics Before and After Choosing Wisely ${ }^{\mathrm{TM}}$}

To the Editor: We thank Dr. Gladwell for his thoughtful comments regarding our article about the impact of the Choosing Wisely campaign on clinical decisions made in primary care clinics. As he notes, achieving value in health care is a critical component of improving our health care system. Thus it is necessary to know what kinds of interventions might be successful at increasing the rates of high-value care.

Space limitations precluded a full discussion of limitations in our study, so we welcome Dr. Gladwell's elaboration of the known limitations of the quasi-experimental design we used. Clinics were not randomly assigned, and all received the educational intervention and exposure to the launch of the Choosing Wisely campaign. We agree that it is not possible to quantify all potential aspects of this exposure. The launch of the Choosing 